\title{
EFEKTIVITAS KOMIK TERHADAP SELF EFFICACYUPAYA PENCEGAHAN KEKERASAN PADA ANAK USIA SEKOLAH
}

\author{
Nuraini Hakim ${ }^{1}$, Ria Anugrahwati ${ }^{2}$ \\ 1,2 Akademi Keperawatan Manggala Husada Jakarta Timur \\ e-mail: nuraini.hakim85@gmail.com
}

\begin{abstract}
In the last three years, there are many child abuse happened to children, that is physically, psychology, and sexual abuse. According to Indonesian Child Protection Commission (KPAI), there are increasing rate of child abuse every year, KP AI monitoring results from 2011 to 2014, there are an increase of violences from 2178 cases to 4311 cases. Children need to know the prevention of sexual violence in a way that is easy and fun so that they can be protected from physical, psychological, or sexual violence. One effort to improve the child's confidence in his ability is by reading comics. This research aims to knowing the effectivity of comic toward self efficacy about child abuse prevention. methodology of this study is using quasy experimental with pre and post test. Analytical test using dependent $t$ test. Population of this research are school age children around 6-10 years old located in Jakarta Timur. The sample were school age children from 6-10 years old amount 18 children. The results of this study obtained pvalue 0.001 (Pvalue <0.05). This indicates that there are significant differences between before and after health education through comic about preventing sexual violence. Advice given to parents is to provide assistance to children to read through comics or other reading sources on violence prevention efforts in children to improve the self efficacy of children.
\end{abstract}

Keywords: self efficacy, child abuse, children

\begin{abstract}
ABSTRAK
Pada kurun waktu tiga tahun terakhir, anak-anak banyak yang mengalami kekerasan, baik secara fisik, psikologis, dan seksual. Menurut komisi Perlindungan Anak Indonesia (KPAI), kekerasan pada anak selalu meningkat setiap tahun. Hasil pemantauan KPAI dari tahun 2011 sampai 2014, terjadi peningkatan dari 2178 kasus hingga 4311 kasus. Anak-anak perlu mengetahui upaya pencegahan kekerasan seksual dengan cara yang mudah dan menyenangkan agar mamput terhindar dari kekerasan fisik, psikis, maupun seksual. Salah satu upaya untuk meningkatkan keyakinan anak terhadap kemampuannya yaitu dengan membaca komik. Penelitian ini bertujuan untuk mengetahui efektifitas komik terhadap self efficacy pencegahan kekerasan pada anak usia sekolah. Penelitian ini menggunakan desain quasi experimental dengan pre dan post test. Populasi anak yang dipilih adalah anak usia sekolah (6-10 tahun) yang berdomisili di Jakarta Timur. Sampel yang digunakan adalah anak usia sekolah (6-10 tahun) sebanyak 18 anak dengan kriteria mampu menulis dan membaca. Instrumen yang digunakan adalah quisioner bertemakan keyakinan diri (self efficacy) terhadap upaya pencegahan kekrasan dengan menggunakan media komik. Anak akan diberikan komik mengenai upaya pencegahan kekerasan, dan dipelajari selama 1 minggu. Setelah itu dilakukan pengukuran self efficacy terhadap pencegahan kekerasan seksual.
\end{abstract}


Analisis data yang digunakan adalah dependent t-test. Hasil penelitian ini ada perbedaan signifikan antara sebelum dan sesudah dilakukan pendidikan kesehatan melalui komik tentang upaya pencegahan kekerasan seksual. Saran yang diberikan kepada orang tua adalah agar melakukan pendampingan pada anak untuk membaca melalui komik atau sumber bacaan lain tentang upaya pencegahan kekerasan pada anak agar meningkatkan self efficacy anak.

Kata kunci: self efficacy, kekerasan pada anak, kekerasan seksual, komik

\section{PENDAHULUAN}

Anak merupakan generasi harapan bangsa yang perlu dilindungi hak-haknya. Hak untuk hidup sehat, hak untuk hidup bahagia, dan mendapat kesejahteraan. Apabila tidak terpenuhi hak-hak tersebut, anak akan mengalami masalah kesehatan. Kekerasan pada anak merupakan masalah kesehatan yang penting dan perlu mendapatkan perhatian yang cukup dari berbagai pihak. Pada kurun waktu 3 tahun terakhir, anak-anak banyak yang mengalami kekerasan, baik secara fisik, psikologis, dan seksual. Menurut komisi Perlindungan Anak Indonesia (KPAI), kekerasan pada anak selalu meningkat setiap tahun. Hasil pemantauan KPAI dari 2011 sampai 2014, terjadi peningkatan yang signifikan. Tahun 2011 terjadi 2178 kasus kekerasan, tahun 2012 ada 3512 kasus, tahun 2013 ada 4311 kasus, dan tahun 2014 ada 5066 kasus (Advianti, 2015).
Menurut data UNICEF saat ini, kekerasan terhadap anak terjadi secara luas di Indonesia, 40 persen anak berusia 13-15 tahun melaporkan pernah diserang secara fisik sedikitnya satu kali dalam setahun. Sebanyak 26 persen melaporkan pernah mendapat hukuman fisik dari orang tua atau pengasuh di rumah. Sebanyak 50 persen anak melaporkan dibully di sekolah, dan sekitar 45 persen perempuan dan anak perempuan di Indonesia percaya bahwa suami/pasangan boleh memukul istri/pasangannya dalam situasi-situasi tertentu. Hal ini menunjukkan kekerasan di Indonesia bisa terjadi pada siapa saja (Karana, 2015). Menurut Kyle dan Carman (2014), kejahatan kekerasan dalam bentuk pembunuhan, perampokan, pemerkosaan, dan serangan yang serius. Anak-anak yang terpajan stressor, seperti kekerasan yang terjadi dalam rumah tangga atau anak yang mengalami tindakan penganiayaan dan pengabaian di masa anak-anak akan 
berisiko tinggi mengalami masalah jangka pendek dan jangka panjang. Kekerasan pada anak dapat terjadi di mana saja, di rumah oleh para orang tua dan anggota keluarga, di sekolah oleh teman atau kakak kelas, atau bahkan guru. Menurut CDC (2010) dalam Kyle dan Carman (2014), kekerasan yang terjadi di sekolah melibatkan intimidasi, dan sebanyak 20\% siswa antara kelas 9 dan 10 di Amerika Serikat diperkirakan menjadi target kejahatan intimidasi yang berulang. Menurut McGuinnes (2007) dalam Kyle dan Carman (2014), banyak kasus intimidasi yang tidak dilaporkan, sementara ini akan berdampak jangka panjang seperti depresi, harga diri rendah, dan ansietas. Selain itu, masalah yang mungkin muncul adalah gangguan tidur, sakit kepala, sakit perut, depresi, asma, enuresis, perilaku agresif, intimidasi teman sebaya, penurunan kompetensi social, menarik diri, menghindari ikatan kasih sayang, regresi perkembangan, ketakutan, ansietas, dan masalah pembelajaran (Shapero, Black, Liu, Kligman, Bender, Abramson, \& Alloy, 2014).

Anak-anak seringkali menjadi korban kekerasan saat berada di lingkungan rumah dan sekolah. Lingkungan yang mengenal anak-anak tersebut cukup dekat. Artinya, pelaku kekerasan pada anak justru lebih banyak berasal dari kalangan yang dekat dengan anak (Setiyawan, 2015). Hal ini sejalan dengan penelitian yang dilakukan oleh Marcdante, Kliegman, Jenson, dan Behrman (2014) bahwasanya diperkirakan sebanyak $1-2 \%$ anak mengalami perlakuan salah secara fisik pada masa kanak-kanak dan sebanyak 2000 anak diantaranya mengalami luka parah setiap tahun, dan seringkali dilaporkan orang tua terutama ibu sebagai pelakunya. Selain itu, setiap tahun tercatat lebih dari 150.000 kasus kekerasan seksual, dan sebanyak 80\% dialami anak perempuan, dan sebagian kecil terjadi pada laki-laki, namun umumnya tidak dapat dikenali atau tidak dilaporkan. Faktor risiko kekerasan seksual meningkat pada anak jenis kelamin perempuan, usia 7-12 tahun, karakteristik keluarga seperti pengguna obat-obatan terlarang dan ketidakharmonisan keluarga, dan kondisi disabilitas (Putnam, 2003 dalam Zeuthen \& Hagelskjaer, 2013).

Kejadian kekerasan pada anak dapat dicegah dengan adanya program-program yang bisa mencegah terjadinya kekerasan seksual. Program tersebut diantaranya 
adalah, mengajari anak untuk mengenali perilaku kekerasan, mengajarkan kemampuan diri agar terhindar dari kekerasan, dan mendorong anak untuk melaporkan kekerasan yang mungkin terjadi (Martyniuk \& Dworkin, 2011). Program tersebut dapat dikemas dalam bentuk pendidikan, permainan, video, boneka, roleplay, dan diskusi (Brasard \& Fiorvanti, 2015). Komik merupakan salah satu media pendidikan yang disukai anak, dan memudahkan anak menerima informasi. Pengembangan inovasi media komik telah banyak dilakukan dan berdampak luar biasa bagi perkembangan pengetahuan (Sudjana, 2002). Komik dapat meningkatkan minat baca seseorang. Hal ini terlihat pada penelitian yang dilakukan oleh Astuti (2015) bahwa terjadi perbedaan peningkatan pengetahuan tentang anemia setelah diberikan intervensi dengan membaca komik. Penelitian yang dilakukan di Yogyakarta menggunakan media komik, karena dirasa sesuai dengan khalayak sasaran, buku komik memiliki sifat personal membuat anak lebih fokus sehingga tepat digunakan untuk media pembelajaran, dan studi ini menyimpulkan bahwa medium buklet dapat diterapkan pada siswa sekolah dasar (SD) sebagai alat pendukung pencegahan kekerasan seksual pada anak (Paramastri, Prawitasari, Prabandari, \& Ekowarni, 2011). Anak-anak yang mengetahui tentang upaya pencegahan kekerasan seksual/fisik diharapkan mampu membela diri saat terjadi kekerasan atau mampu mengenali risiko perilaku kekerasan.

Kemampuan diri pada anak untuk melakukan pencegahan kekerasan seksual dapat dilakukan jika anak memiliki self efficacy (keyakinan diri). Self efficacy menurut Bandura (1997) dalam Malow, Devieux, dan Luciko (2006) adalah pengukuran individu terhadap kemampuannya untuk menyelesaikan tugas spesifik. self efficacy mempengaruhi cara kehidupan individu dalam kehidupan sehari-hari, mengatasi hubungan satu sama lain, menentukan upaya melindungi diri dari kondisi yang berisiko. Penelitian yang dilakukan oleh Farrel and Walsh (2010) di Amerika Serikat mengenai pendidikan tentang kekerasan dapat meningkatkan pengetahuan dan membantu mempercepat pengenalan terhadap kekerasan pada anak. Peran perawat sangat penting untuk dapat memfasilitasi upaya pencegahan kekerasan seksual pada anak.Berdasarkan uraian di atas, penulis tertarik untuk mengidentifikasi efektifitas 
komik tentang pendidikan seks terhadap self efficacy pada anak usia sekolah dalam upaya pencegahan kekerasan seksual pada anak.

\section{METODE PENELITIAN}

Penelitian ini menggunakan desain penelitian quasi eksperimental, pre dan post test pada satu kelompok sampel. Penelitian ini bertujuan untuk melihat perbandingan self efficacy pada kelompok anak usia sekolah sebelum dan sesudah dilakukan pendidikan kesehatan menggunakan komik. Populasi anak yang dipilih adalah anak usia sekolah (6-10 tahun) yang berdomisili di Jakarta Timur, dilakukan pada Juli 2017. Sampel yang digunakan adalah anak usia sekolah (6-10 tahun) sebanyak 18 anak dengan kriteria mampu menulis dan membaca. Instrumen yang digunakan adalah quisioner bertemakan keyakinan diri (self efficacy) terhadap upaya pencegahan kekerasan dengan menggunakan media komik. Anak akan diberikan komik mengenai upaya pencegahan kekerasan, dan dipelajari selama 1 minggu. Setelah itu dilakukan pengukuran self efficacy terhadap pencegahan kekerasan seksual. Analisis data yang digunakan adalah menggunakan uji dependent t-test.

\section{HASIL}

Berdasarkan Tabel 1 dapat diketahui bahwa karakteristik ibu sebagian besar berada pada tingkat pendidikan SMP, berusia 31-40 tahun, sebagai ibu rumah tangga, dan memiliki penghasilan keluarga sebesar 2-3 juta. Karakteristik anak dapat terlihat sebagian besar jenis kelamin perempuan, berusia 7-9 tahun, dan berada pada kelas 1-2 sekolah dasar.

Berdasarkan Tabel 2 diketahui korelasi karakteristik pendidikan ibu dengan self efficacy anak memiliki nilai $\mathrm{r}-0,390$ dan pvalue 0,108. Hal ini menunjukkan tidak terdapat hubungan antara kedua variabel. Korelasi penghasilan keluarga dengan self efficacy memiliki nilai r 0,095 dan pvalue 0,78 , ini berarti tidak terdapat hubungan yang lemah antara penghasilan keluarga dan self efficacy anak. Korelasi usia ibu dengan self efficacy memiliki nilai r 0,146 dan pvalue 0,53, ini menunjukkan tidak terdapat hubungan antara kedua variabel. Korelasi pekerjaan ibu dengan self efficacy memiliki nilai $\mathrm{r}-0,390$ dan pvalue 0,109, ini berarti tidak terdapat hubungan terhadap kedua variabel. 
Tabel 1. Distribusi Karakteristik Respoden BerdasarkanPendidikan Terakhir Penghasilan Keluarga, Usia Ibu, Jenis Kelamin, Usia anak, Kelas, dan Pekerjaan Ibu, di DKI Jakarta, Bekasi dan Tangerang Tahun $2017(\mathrm{n}=18)$

\begin{tabular}{lcc}
\hline \multicolumn{1}{c}{ Variabel } & $\mathrm{N}$ & $\%$ \\
\hline 1. Pendidikan Ibu & 10 & 55,6 \\
a. Pendidikan SMP & 4 & 22,2 \\
b. Pendidikan SMA & 0 & 0 \\
c. Pendidikan D3 & 4 & 22,2 \\
d. Pendidikan S1 & & \\
2. Penghasilan Keluarga & 8 & 44,4 \\
a. 2-3 juta & 2 & 11,1 \\
b. Lebih dari 3-4 juta & 2 & 11,1 \\
c. lebih dari 4-5 juta & 6 & 33,3 \\
d. lebih dari 5 juta & & \\
3. Usia Ibu & 5 & 27,8 \\
a. 20-30 tahun & 11 & 61,1 \\
b. 31-40 tahun & 2 & 11,1 \\
c. 41-50 tahun & & \\
4. Jenis Kelamin & 5 & 27,8 \\
a. Laki-laki & 13 & 72,2 \\
b. Perempuan & & \\
5. Usia Anak & 15 & 16,7 \\
a. 7-9 & 3 & 63,3 \\
b. >10 & & 33,3 \\
6. Kelas & 12 & 66,7 \\
a. 1-2 SD & 6 & \\
b. 3-4 SD & 12 & \\
7. Pekerjaan Ibu & 6 & \\
a. IRT & & \\
b. Bekerja & & \\
\hline
\end{tabular}

Tabel 2 Hubungan Karakteristik Pendidikan Terakhir Penghasilan Keluarga, Usia Ibu, Jenis Kelamin, Usia anak, Kelas, dan Pekerjaan Ibu dengan self efficacy, di DKI Jakarta, Bekasi dan Tangerang Tahun 2017( $\mathrm{n}=18)$

\begin{tabular}{lcc}
\hline \multicolumn{1}{c}{ Variabel } & $\mathrm{R}$ & Pvalue \\
\hline Pendidikan Ibu & $-0,390$ & 0,108 \\
Penghasilan Keluarga & 0,095 & 0,78 \\
Usia Ibu & 0,146 & 0,53 \\
Jenis Kelamin & 0,256 & 0,306 \\
Usia Anak & 0,097 & 0,72 \\
Kelas & 0,175 & 0,533 \\
Pekerjaan Ibu & $-0,390$ & 0,109 \\
\hline
\end{tabular}

Berdasarkan Tabel 2 dapat diketahui bahwa korelasi karakteristik jenis kelamin memiliki nilai r 0,256 dan pvalue 0,306, ini menunjukkan tidak terdapat hubungan 
antara kedua variabel tersebut. Korelasi usia anak memiliki nilai r 0,097 dan pvalue 0,72 , ini berarti tidak ada hubungan antar kedua variabel. Korelasi kelas pada anak memiliki nilai r 0,175 dan pvalue 0,109, ini menunjukkan tidak ada hubungan antar kedua variabel. Perbedaan rerata self

Tabel 3. Perbedaan Rerata Self Efficacy Sebelum dan Sesudah Pendidikan Kesehatan Melalui Komik

\begin{tabular}{lllll}
\hline Self efficacy & $\mathrm{N}$ & Mean & SD & pvalue \\
\hline Sebelum & 18 & 64,44 & 8,382 & 0,001 \\
Sesudah & 18 & 71,06 & 6,629 & \\
\hline
\end{tabular}

Berdasarkan Tabel 3 dapat dijelaskan bahwa rata-rata self efficacy pada responden setelah mengikuti intervensi pendidikan kesehatan melalui komik terjadi peningkatan rerata sebesar 6,62. Hasil pvalue 0,001 (pvalue<0,05) menunjukkan ada perbedaan yang bermakna terhadap rata-rata self efficacy anak terhadap upaya pencegahan kekerasan.

\section{PEMBAHASAN}

Tujuan penelitian ini adalah mengidentifikasi perbedaan self efficacy pada anak sebelum dan sesudah dilakukan pendidikan kesehatan melalui komik. Hasil penelitian yang didapatkan yaitu terdapat peningkatan rerata self efficacy sebanyak 6,62 dan pvalues 0,001. Hal tersebut menggambarkan adanya pengaruh yang signifikan antara efficacy sebelum dan sesudah pendidikan kesehatan melalui komik (analisis bivariat). Analisis ini bertujuan menggambarkan rerata self efficacy anak tehadap upaya pencegahan kekerasan sebelum dan sesudah membaca komik. 
Ekowarni, 2011 menggunakan media komik, karena dirasa sesuai dengan anak usia sekolah, buku komik memiliki sifat personal membuat anak lebih fokus sehingga tepat digunakan untuk media pembelajaran, dan studi ini menyimpulkan bahwa medium buklet dapat diterapkan pada siswa sekolah dasar (SD) sebagai alat pendukung pencegahan kekerasan seksual pada anak. Faktor lain yang turut mempengaruhi hasil adalah dikarenakan saat membaca komik, orang tua ikut mendampingi anak sehingga terjadi transfer knowledge dari orang tua ke anak. Hal ini dikarenakan orang tua lebih memiliki wawasan dan pengalaman mengenai kekerasan yang terjadi pada anak, sehingga dapat meningkatkan self efficacy anak.

Hal di atas sejalan dengan pernyataan Bandura (1994) hal yang dapat mempengaruhi keyakinan diri seseorang adalah pengalaman diri sendiri, pengalaman orang lain yang dirasakan oleh diri sendiri, persuasi emosi dan verbal, dan perubahan fisik (Bandura, 1994). Menurut Bandura (1997) hal yang paling kuat mempengaruhi self efficacy adalah pengalaman diri. Pengalaman diri tersebut dapat ditingkatkan dengan menguasai suatu pengalaman tertentu.
Sejalan dengan pernyataan Palmer (2006) dalam Matta dan Jarvella (2013) yaitu pada anak sekolah, penguasaan dapat dilakukan dengan menyelesaikan tugas, menginterpretasi, dan menilai hasilnya. Interpretasi ini dapat menciptakan penilaian anak dari kompetensi tertentu dan meningkatkan kepercayaan diri dalam menyelesaikan tugas yang hampir sama maupun berbeda (Usher, 2008 dalam Matta dan Jarvella (2013)).

Pengalaman diri tersebut dapat diperoleh dengan membaca komik. Komik merupakan media yang dapat menambah pengetahuan dan pengalaman, melakukan interpretasi, dan menilai hasil yang ada. Menurut Sudjana (2002) komik merupakan media komunikasi yang kuat. Fungsi yang bisa dimanfaatkan media komik antara lain adalah untuk informasi pendidikan. Komik harus memiliki alur cerita yang menarik bagi pembaca. Komik dapat dijadikan media pilihan yang digunakan oleh pendidik sebagai media inovatif. Pengembangan inovasi media komik telah banyak dilakukan dan berdampak luar biasa bagi perkembangan pengetahuan. Anak usia sekolah yang memiliki banyak pengetahuan akan meningkatkan self efficacy seorang anak terhadap suatu hal, dalam hal ini terhadap 
upaya pencegahan kekerasan pada anak. Efektivitas komik ini sejalan dengan penelitian yang dilakukan oleh Sari, Berniyanti, dan Laksminiwati (2012) yaitu komik dapat meningkatkan pengetahuan anak terhadap pencegahan karies gigi. Penelitian lain yang dilakukan oleh Hamida, Siti, dan Mutalazihah (2012) terjadi peningkatan pengetahuan pada anak usia sekolah mengenai gizi seimbang setelah dilakukan intervensi menggunakan komik. Pengetahuan yang cukup dapat meningkatkan self efficacy seseorang dalam suatu kompetensi.

\section{KESIMPULAN}

Terdapat perbedaan yang signifikan (peningkatan) pada skor rerata self efficacy terhadap pencegahan kekerasan pada anak sebelum dan sesudah diberikan pendidikan kesehatan melalui komik. Komik merupakan bacaan yang paling sesuai dengan karakteristik anak usia sekolah.

Saran yang diberikan untuk masyarakat terutama orang tua, adalah menyediakan bacaan atau sumber belajar mengenai pencegahan kekerasan dan mendampingi anak untuk membaca komik tersebut sehingga dapat melakukan transfer knowledge dengan mudah.

\section{REFERENSI}

Bandura, A. (1994). Self efficacy beliefs of adolescents. USA: Information age publishing

Bandura, A. (2005). Self efficacy beliefs of adolescents. USA: Information age publishing

Hamida, K., Siti, Z., \& Mutalazihah (2012). Penyuluhan gizi dengan media komik untuk meningkatkan pengetahuan tentang keamanan makanan jajanan. Jurnal Kesehatan Masyarakat, Kemas, 67-73. diunduh Juni 2014. http://journal.unnes.ac.id/nju/i ndex.php/kemas

Jarvel, S. \& Maatta, E. (2013). Involving children in reflective discussions abouttheir perceived selfefficacy and learning experiences. International Journal of Early Years Education Vol. 21, No. 4, 309-324, http:/ /dx.doi.org/10.1080/0966 9760.2013 .867836

Paramastri, I., Prawitasari, J.E., Prabandari, Y.S., Ekowarni, E. 
(2011). Buklet sebagai Media

Pencegahan terhadap Kekerasan

Seksual pada Anak-anak.

Kesmas, Jurnal Kesehatan

Masyarakat Nasional. Vol. 6, No.

2.

Shapero, B.G., Black, S.K, Liu, R.T., Klugman, J., Bender, R.E., Abramson, L.Y., \& Alloy, L.B. (2014). Stresful life events and depression symptoms: the effect of childhood emotional abuse on stress reactivity. J. Clin. Pshycol, 70, 209-223.

Setiyawan, D. (2015). KPAI: Pelaku kekerasan terhadap anak. diunduh tanggal 10 Maret 2017. http://www.kpai.go.id/berita/k pai-2014-ada-622-kasuskekerasan-anak/

Sudjana, N. \& Rivai, A. (2002). Media pengajaran. Bandung

Tirosh,D., Tsamir, P., Levenson, E., Tabach, M.,\& Barkai, R. (2012). Exploring young children's self efficacy beliefs related to mathematical and nonmathematical tasks performed in kindergarten: abused and neglected children and their peers. Educ Stud Math,
83, 309-322. DOI 10.1007/s106490129458y

Zeuthen, K., Hagelskjaer, M. (2013). Prevention and intervention: prevention of child sexual abuse: analysis and discussion of the field. Journal of child sexual abuse, 22, 744-760. DOI. 10.1080/105387132. 